\title{
Local and Systemic Immunity Research of Herpetic and Chlamydial-Herpetic Infection
}

Elena Vladimirovna Markelova ${ }^{1}$, Natalia Sergeevna Chepurnova ${ }^{1}$, Marina Sergeevna Tulupova ${ }^{2}$, Alexander Viktorovich Karaulov ${ }^{3}$, Elena Valeryevna Baybarina ${ }^{1}$, Kirill Vasilyevich Teterlev ${ }^{1}$ and Valeria Vologina ${ }^{1}$

1. Department of Normal and Pathological Physiology, Pacific State Medical University, Ministry of Healthcare of the Russian Federation, Vladivostok 690002, Russian Federation

2. Department of Obstetrics and Gynaecology with Course of Perinatology, Peoples' Friendship University of Russia, Ministry of Education and Science of the Russian Federation, Moscow 11719, Russian Federation

3. Department of Clinical Immunology and Allergology, I.M. Sechenov First Moscow State Medical University, Ministry of Healthcare and Social Development of the Russian Federation, Moscow 119991, Russian Federation

\begin{abstract}
Investigation of the immune status and TNF- $\alpha$, IFN $\gamma$ and IL-10 concentration in the ejaculate and venous blood serum of 100 men with STI (marked as main group (MG)) has been conducted. MG men were divided into 2 subgroups: 50 men with chronic viral urethritis (genital herpes - herpetic urethritis (HU)) and 50 patients with c viral-bacterial urethritis (genital herpes, associated with chlamydiosis-herpetic-chlamydial urethritis (HCU)). Comparative group (control group) were included 20 apparently healthy male-volunteers. More perceptible disfunctions of the local and systemic immunity have been revealed in patients with viral-bacterial urethritis: elevating of $\mathrm{CD} 3+\mathrm{CD} 25+$ expression as well as indicators of late negative activation markers have been recorded on the background of phagocytosis indicators reducing, reliable rising of TNF $\alpha$ level in the venous blood serum have been marked, similar cytokine level in the ejaculate has been considerably higher as compared with the herpetic urethritis group and controls; also IFN $\gamma /$ IL-10 ratio lowering has been noted either in the venous blood serum, or in the seminal fluid compared with the control group.
\end{abstract}

Key words: Immune status, cytokines, ejaculate, herpes, chlamydiosis.

\section{Introduction}

Structural analysis of the Sexually transmitted infection (STI) has shown genital herpes to be more often associated with the chlamydial infection, being accounted by common epidemiological patterns, peculiar to the agents of STI [1,2]. A large scope of the urogenital infection studies is dedicated mainly to monoinfection variants, or literature data focus on the immunological characteristics as well as therapeutic variants of some urogenital infection combinations. At the same time, mix-urethritis, particularly of the chlamydial-herpetic etiology, is rater poor elucidated, without proper reflection of the immune disturbances and correction potentialities in this category of male

Corresponding author: Elena Vladimirovna Markelova, Ph.D., professor, research field: clinical immunology. patients.

\section{Materials and Methods}

Sexually transmitted infection clinical trial (STI) of 100 male has been conducted according to common standards. Main group patients (MG) were divided into 2 subgroups: 50 men with chronic viral urethritis (genital herpes - herpetic urethritis (HU)) and 50 men with $\mathrm{c}$ viral-bacterial urethritis (genital herpes, associated with chlamydiosis-herpetic-chlamydial urethritis (HCU)), MG mean age being $33.0 \pm 4.2$ years. Comparative group (control group) were included 20 healthy male-volunteers, aged $26.5 \pm 1.1$ years. Lymphocytes phenotyping and phagocytosis indicators have been estimated with the method of the running cytoflowmetry using monoclonal antibodies (BD Biosciences) (the USA). TNF- $\alpha$, IFN $\gamma$ and IL-10 
content have been detected by means of specific reagent of the company (R\&D Diagnostics Inc.) (the USA) with the method of sandwich option of Enzyme Linked Immunosorbent Assays methodology. Results record was made by means of the enzymoimmunoassay on the (Multiscan) (Finland), quantity was expressed in picogram $/ \mathrm{ml}$ ( $\mathrm{pg} / \mathrm{ml})$. Ejaculate examination was produced as per WHO Protocol (5th edition, 2010). Material statistic handling was made by means of the applied program package "STATGRAPHICS" with the method of variation statistics using two-sample Student's test and Mann Whitney U-test $\left(\mathrm{p}_{\mathrm{u}}\right)$. On normal distribution random variables were indicated as mean values, standard deviations $(X \pm \sigma)$. Quantitative attributes without normal distribution were as median (Me), $25 \%$ and $75 \%$ quartiles (Q25; Q75). Statistical significance level, rejecting zero hypotheses, was less 0.05 .

\section{Results}

CD markers choice and their combination were based on the evaluation of the main lymphocyte population (T-, B-, NK-, NKT-cells), as well as markers of the positive $\left(\mathrm{CD} 25^{+}\right.$, $\left.\mathrm{HLA} \mathrm{DR}^{+}\right)$and negative $\left(\mathrm{CD}^{\circ} 5^{+}\right)$lymphocyte activation. The quantitative analysis of the main lymphocyte subpopulation has been performed: T-helpers (CD3+ CD4+) and cytoxicity T-cells (CD3+ CD8+). Subdividing males under the investigation into two examined groups: (herpetic and herpetic-chlamydial urethritis) and analyzing of immunogram main indices, general patterns and peculiarities were found (Table 1.). In the examined groups, there were no statistically significant distinctions of the CD3+CD4+ (T-helpers) and $\mathrm{CD} 3+\mathrm{CD} 8+(\mathrm{T}-$ cytoxicity) in the peripheral blood levels. While in co-infection CD3+CD8+ lymphocyte specific weight was statistically significantly less than in controls. Correlation analysis of the lymphocytes, carrying markers of the mature $\mathrm{T}$-helpers and cytoxicity T-cells $(\mathrm{CD} 3+\mathrm{CD} 4+/ \mathrm{CD} 3+\mathrm{CD} 8+)$ also has not revealed statistically meaningful alterations in the both groups; it should be noted that immunoregulatory index values (IRI) in toto did not exceed reference values. Immunocyte activation markers expression value enabled to expose the essential discrepancies in the groups of investigation. It has been shown that CD25+ lymphocyte number increased in the majority of patients (34 persons (68\%) with HU and 41 persons (82\%) with $\mathrm{HCU})$. In mixed bacterial-viral urethritis significant increase of the CD3+ CD25+ expression and an increase of the late negative activation markers indices (CD3+ CD95+) have been found, while HLA DR immunocyte antigen expression had no statistically significant alterations and differences from the reference values. Statistically significant alterations in the natural killers' level, as well as lymphocyte minor population number, expressing isochronously $\mathrm{CD} 3+$ CD16+ CD56+ markers, relating to NKT-cells, have not been defined. Phagocytic link analysis has shown phagocytosis quantitative indices to be statistically significantly reduced in males with $\mathrm{HCU}$, when compared with the control group.

There was found a considerable elevation in the venous blood serum of the levels of TNF $\alpha$ and IL-10 both in the group of patients with viral urethritis: 10.9 (7.4; 22.5) PG/ml and 22.76 (11.31; 54.02) PG/ml, and in the group with viral-bacterial urethritis: 10.4 (6.9; 25.4) $\mathrm{PG} / \mathrm{ml}$ and 24.12 (15.88; 32.62) $\mathrm{PG} / \mathrm{ml}$, correspondingly, when compared with the control group ( $\left.\mathrm{p}_{\mathrm{u}}<0.001\right)$. IFN $\gamma$ level in both groups under the investigation did not exceed the limits of the reference values (Table 2).

During the investigation of cytokine level in the ejaculate, IL-10 number in the group with viral urethritis $19.51(10.22 ; 116.11) \mathrm{PG} / \mathrm{ml}$ was registered as significantly higher the limits of the reference values $\left(\mathrm{p}_{\mathrm{u}}<0.05\right)$ (Table 3). While TNF $\alpha$ level in the ejaculate was significantly higher only in the group of males with bacterial-viral urethritis comparing with the group of males with the herpetic urethritis and the control group, $6.92(4.34 ; 9.47) \mathrm{PG} / \mathrm{ml}\left(\mathrm{p}_{\mathrm{u}}<0.01\right)$ as against $4.31(3.01 ; 4.55) \mathrm{PG} / \mathrm{ml}$ and $2.22(1.53 ; 3.71) \mathrm{PG} / \mathrm{ml}$, 
Table 1 The results of the immunocompetent blood cells immunophenotyping and phagocytosis indices in patients with chronic urethritis.

\begin{tabular}{|c|c|c|c|c|}
\hline \multirow{2}{*}{ Index } & & \multicolumn{2}{|c|}{$\begin{array}{l}\text { Patients with urethritis } \\
n=100\end{array}$} & \multirow{2}{*}{$\begin{array}{l}\text { Healthy males } \\
n=20\end{array}$} \\
\hline & & $\begin{array}{l}\mathrm{HU} \\
n=50\end{array}$ & $\begin{array}{l}\mathrm{HCU} \\
n=50 \\
\end{array}$ & \\
\hline \multirow{2}{*}{$\mathrm{CD}^{+} \mathrm{CD} 19^{+}$} & $\%$ & $69.23 \pm 2.51$ & $70.82 \pm 1.52$ & $70.30 \pm 2.15$ \\
\hline & $\mathrm{TC} / 10^{9} / 1$ & $1.01 \pm 0.07$ & $1.33 \pm 0.12$ & $1.42 \pm 0.14$ \\
\hline \multirow{2}{*}{$\mathrm{CD}^{+} \mathrm{CD}^{+}$} & $\%$ & $42.00 \pm 1.87$ & $38.06 \pm 2.05^{* *}$ & $47.50 \pm 2.20$ \\
\hline & $\mathrm{TC} / 10^{9} / 1$ & $0.64 \pm 0.03$ & $0.69 \pm 0.07$ & $0.96 \pm 0.10$ \\
\hline \multirow{2}{*}{$\mathrm{CD}^{+} \mathrm{CD}^{+}$} & $\%$ & $25.08 \pm 0.89$ & $28.70 \pm 1.98$ & $31.10 \pm 1.90$ \\
\hline & $\mathrm{TC} / 10^{9} / 1$ & $0.39 \pm 0.02$ & $0.53 \pm 0.06$ & $0.62 \pm 0.11$ \\
\hline \multirow{2}{*}{$\mathrm{CD}^{-} \mathrm{CD}^{-} 9^{+}$} & $\%$ & $13.62 \pm 1.18$ & $11.88 \pm 0.81 *$ & $14.92 \pm 1.26$ \\
\hline & $\mathrm{TC} / 10^{9} / 1$ & $0.20 \pm 0.02$ & $0.22 \pm 0.02$ & $0.30 \pm 0.05$ \\
\hline \multirow{2}{*}{$\mathrm{CD}^{-} 16^{+} 56^{+}$} & $\%$ & $13.40 \pm 1.98$ & $14.15 \pm 1.32$ & $13.85 \pm 0.80$ \\
\hline & $\mathrm{TC} / 10^{9} / 1$ & $0.22 \pm 0.05$ & $0.25 \pm 0.02$ & $0.28 \pm 0.07$ \\
\hline \multirow{2}{*}{$\mathrm{CD}^{+} \mathrm{CD} 16^{+} 56^{+}$} & $\%$ & $5.19 \pm 1.27$ & $5.26 \pm 1.33$ & $3.44 \pm 0.06$ \\
\hline & $\mathrm{TC} / 10^{9} / 1$ & $0.08 \pm 0.02$ & $0.09 \pm 0.02$ & $0.07 \pm 0.02$ \\
\hline \multirow{2}{*}{$\mathrm{CD} 25^{+}$} & $\%$ & $13.69 \pm 1.28 * * *$ & $16.23 \pm 1.19 * * *$ & $9.12 \pm 0.82$ \\
\hline & $\mathrm{TC} / 10^{9} / 1$ & $0.21 \pm 0.02$ & $0.31 \pm 0.04$ & $0.20 \pm 0.07$ \\
\hline \multirow{2}{*}{$\mathrm{CD}^{+} \mathrm{CD} 25^{+}$} & $\%$ & $\begin{array}{l}7.53 \pm 0.92 \\
\mathrm{p}_{\mathrm{u} 1-2}<0.05\end{array}$ & $10.30 \pm 0.86^{* * *}$ & $6.15 \pm 0.70$ \\
\hline & $\mathrm{TC} / 10^{9} / 1$ & $\begin{array}{l}0.11 \pm 0.01 \\
\mathrm{p}_{\mathrm{u} 1-2}<0.05\end{array}$ & $0.20 \pm 0.03 *$ & $0.14 \pm 0.04$ \\
\hline \multirow{2}{*}{$\mathrm{CD} 5^{+}$} & $\%$ & $23.38 \pm 2.30 *$ & $23.77 \pm 2.67 *$ & $16.20 \pm 1.20$ \\
\hline & $\mathrm{TC} / 10^{9} / 1$ & $0.36 \pm 0.03$ & $0.42 \pm 0.05$ & $0.32 \pm 0.06$ \\
\hline \multirow{2}{*}{$\mathrm{CD}^{+}{ }^{+} \mathrm{CD} 95^{+}$} & $\%$ & $15.36 \pm 1.81 * *$ & $16.35 \pm 2.34 * * *$ & $7.14 \pm 0.12$ \\
\hline & $\mathrm{TC} / 10^{9} / 1$ & $0.23 \pm 0.02 *$ & $0.30 \pm 0.05^{*}$ & $0.15 \pm 0.03$ \\
\hline \multirow{2}{*}{ HLA-DR ${ }^{+}$} & $\%$ & $15.37 \pm 1.30$ & $14.62 \pm 0.74$ & $13.90 \pm 0.86$ \\
\hline & $\mathrm{TC} / 10^{9} / 1$ & $0.24 \pm 0.02$ & $0.27 \pm 0.02$ & $0.28 \pm 0.06$ \\
\hline \multirow{2}{*}{$\mathrm{CD}^{+}{ }^{+} \mathrm{HLA}_{-} \mathrm{DR}^{+}$} & $\%$ & $2.26 \pm 0.28$ & $2.74 \pm 0.28$ & $4.00 \pm 0.62$ \\
\hline & $\mathrm{TC} / 10^{9} / 1$ & $0.03 \pm 0.002$ & $0.05 \pm 0.008$ & $0.09 \pm 0.02$ \\
\hline $\begin{array}{l}\mathrm{IRI} \\
\mathrm{CD}^{+} / \mathrm{CD}^{+}\end{array}$ & & $1.69 \pm 0.09$ & $1.55 \pm 0.16$ & $1.55 \pm 0.15$ \\
\hline Phagocytic index & $\%$ & $66.31 \pm 4.55$ & $64.18 \pm 4.62 *$ & $76.3 \pm 1.4$ \\
\hline Phagocytic number & & $3.80 \pm 0.38$ & $3.62 \pm 0.41 *$ & $4.80 \pm 0.20$ \\
\hline
\end{tabular}

${ }^{*} \mathrm{p}_{\mathrm{u}}<0.05 ; * * \mathrm{p}_{\mathrm{u}}<0.01 ; * * * \mathrm{p}_{\mathrm{u}}<0.001$-statistical significance of the differences with the control group;

$\mathrm{p}_{\mathrm{u} 1-2}$ - compared groups of the male patients with urethritis.

Table 2 Cytokine level in the venous blood serum of the examined patients of different groups.

\begin{tabular}{llcl}
\hline Studied indices & \multicolumn{2}{c}{ Patients SG, $n=100$} & Control group, $n=20$ \\
\cline { 2 - 4 } & HU, $n=50$ & HCU, $n=50$ & $2.4(1.8 ; 3.7)$ \\
Me(Q25; Q75) & $10.9(7.4 ; 22.5)^{* * *}$ & $10.4(6.9 ; 25.4)^{* * *}$ & $9.34(5.95 ; 13.87)$ \\
IFN $\gamma$, PG/ml & $9.13(5.61 ; 11.36)$ & $9.62(6.72 ; 14.2)$ & $11.48(9.22 ; 12.62)$ \\
Me(Q25; Q75) & $22.76(11.31 ; 54.02)^{* * *}$ & $24.12(15.88 ; 32.62)^{* * *}$ & \\
IL-10, PG/ml & Me(Q25; Q75) &
\end{tabular}

${ }^{*} \mathrm{p}_{\mathrm{u}}<0.05 ;{ }^{* *} \mathrm{p}_{\mathrm{u}}<0.01 ;{ }^{* *} \mathrm{p}_{\mathrm{u}}<0.001$-statistical significance of the differences with the control group;

$\mathrm{p}_{\mathrm{u} 1-2}$ - compared groups of the male patients with urethritis. 
Table 3 Cytokine level in the ejaculate of the examined patients in the different groups.

\begin{tabular}{llll}
\hline \multirow{2}{*}{ Studied indices } & \multicolumn{2}{c}{ Patients SG, $n=100$} & Control group, $n=20$ \\
\cline { 2 - 4 } & HU, $n=50$ & HCU, $n=50$ & $2.22(1.53 ; 3.71)$ \\
TNF $\alpha$, PG/ml $25 ;$ Q75) & $4.31(3.01 ; 4.55)$ & $6.92(4.34 ; 9.47)^{* *}$ & $18.69(16.31 ; 21.71)$ \\
IFN $\gamma$, PG/ml & $p_{u 1-2}<0.05$ & $14.96(14.44 ; 17.08)$ & $10.1(8.9 ; 11.3)$ \\
Me(Q25; Q75) & $15.21(13.15 ; 16.09)$ & $17.13(16.33 ; 118.65)^{* * *}$ & \\
IL-10, PG/ml & $19.51(10.22 ; 116.11)^{* * *}$ & Me(Q25; Q75) &
\end{tabular}

${ }^{*} \mathrm{p}_{\mathrm{u}}<0.05 ;{ }^{* *} \mathrm{p}_{\mathrm{u}}<0.01 ; * * * \mathrm{p}_{\mathrm{u}}<0.001$-statistical significance of the differences with the control group;

$\mathrm{p}_{\mathrm{u} 1-2}$ - compared groups of the male patients with urethritis.

Table 4 IFN $\gamma /$ IL-10 ratio in the venous blood serum and in the ejaculate in the study groups and in the controls.

\begin{tabular}{llll}
\hline Examined & \multicolumn{2}{c}{ Patients SG, $n=100$} & Control group, $n=20$ \\
\cline { 2 - 4 } biological fluid & $\mathrm{HU}, n=50$ & $\mathrm{HCU}, n=50$ & $0.92 \pm 0.07$ \\
\hline Venous blood serum & $0.3 \pm 0.05^{*}$ & $0.28 \pm 0.08^{* *}$ & $1.88 \pm 0.06$ \\
Ejaculate & $0.23 \pm 0.03^{* * *}$ & $0.34 \pm 0.02^{* * *}$ &
\end{tabular}

${ }^{*} \mathrm{p}_{\mathrm{u}}<0.05 ;{ }^{* *} \mathrm{p}_{\mathrm{u}}<0.01 ; * * * \mathrm{p}_{\mathrm{u}}<0.001$-statistical significance of the differences with the control group;

$\mathrm{p}_{\mathrm{u} 1-2}$ - compared groups of the male patients with urethritis.

pro tanto. IFN $\gamma$ index did not significantly differentiate as of the control values as between the groups under the investigation.

Along with IFN $\gamma / \mathrm{IL}-10$ content in the venous blood serum and in the ejaculate of the groups, IFN $\gamma / \mathrm{IL}-10$ ratio was analyzed, reflecting cellular immune response prevalence (Table 4). Ratio serum level in the both groups of males was not statistically different, although was reliably reduced relative to the control group. Apparent reducing of the IFN $\gamma / \mathrm{IL}-10$ ratio in the ejaculate of males with the viral and mixed urethritis when compared with the control group has been estimated.

\section{Discussion}

$\mathrm{CD} 3+\mathrm{CD} 8+$ lymphocytes are known to generate synaptic patterns with the neurons and are able to block the reactivation of the herpetic infection [3]. Like this, in the group with the mixed urethritis, $\mathrm{CD} 3+\mathrm{CD} 8+$ lymphocytes specific weight was statistically noticeable lower than in the control group, enabling to reactivate the herpetic infection.

In the mixed bacterial-viral urethritis significant increase of $\mathrm{CD} 3+\mathrm{CD} 25+$ expression and the late negative activation markers (CD3+ CD95+) was found, while HLA DR antigen expression on immunocytes was not statistically considerably exchanged and did not differ from the control values, evidencing of the switch disturbances in the activation processes from the early to the late one, and might reflect T-cell immunity functional defect.

Natural killers, perforin-dependent lysis and cytokine production ensure the protectant immune response [4]. Statistically significant differences in natural killers levels, as well as minor lymphocyte population content, isochronally expressing CD3+ CD16+ CD56+markers, referring to NKT-cells, were not found, indicating both the low ability of the infected cells killing by means of perforins and granzins, and insufficient regulation of IFN $\gamma$ synthesis.

Phagocytosis quantitative indices were reliably reduced in males with $\mathrm{HCU}$, as compared to the controls, indicating the chronic urethritis character and depletion of important part of the innate immunity resources.

Reliable increase of the anti-inflammatory mediator $\mathrm{TNF} \alpha$ in the venous blood serum was noted in the both groups of males under investigation. TNF $\alpha$ is known to give death signal through TNF $\alpha 1$ type receptor (p55) and Fas-antigen (Apo-1, CD95+), initiating interaction of the death domains receptor with adapter protein FADD (FasR-associated death domain) and TRADD 
(TNFR-associated death domain) and caspase-8 [3-5]. Elevated TNF $\alpha$ concentration, required to start apoptogenic signal, indirectly evidences of the apoptosis activation. While TNF $\alpha$ level in the ejaculate was significantly increased only in the male group with bacterial-viral urethritis, comparing with the male group with herpetic urethritis and the control group. $\mathrm{TNF} \alpha$ is known for a long time to suppress chlamydial infection and to play an important role in the early chlamydia elimination, not associated with IFN $\gamma[6,7]$. In this connection, TNF $\alpha$ hyperproduction in the $\mathrm{c}$ viral-bacterial urethritis subgroup could be considered as a compensatory mechanism, but their high apostolic activity is not excluded, enabling chronic inflammation maintenance and the impaired fertility.

IL-10 indices statistically exceeded control values in both groups of patients as in the venous blood serum, and in the ejaculate. IL-10 level increasing is known to activate natural killers; however in the study groups we have not noted the increased level of both the natural killers and the lymphocyte minor population, isochronally expressing CD3+ CD16+ CD56+ markers, evidencing, in our view, the prolonged character of the infection.

Outcome of the chlamydial infection, resulting in a complete recovery or in a development of complications, is considered to be impacted by a balance of IFN $\gamma$ and IL-10 level of production. IL-10 secretion is significantly elevated in long-lasting infection. IL-10 inhibits in phagocytes and in APC transcription and production of cytokines, responsible for inflammatory response (TNF, IL-12 and others) [2, 5]. Reduced expression of IL-10 results in the balance alteration between T-helpers of the first and second type to the side of the first of these, and, respectively, to more marked T-cell response. Thus, it is difficult for the researchers to answer unequivocally which of cell response in urogenital chlamydiosis plays a leading role, Th-1 or Th-2. We should take into consideration, that in STI, T-helper response transformation is mainly observed aside T-helpers of the second type, responsible for the humoral antigen-specific immune formation, accompanied by the increased anti-inflammatory mediator production and macrophage capacity reducing to interferon production. We have noted expressed reducing of the IFN $\gamma /$ IL-10 ratio both in the venous blood serum, and in the semen of males with viral and mixed urethritis comparing with the control group, evidencing dysregulation of the immune response on the local and systemic levels in this patient category.

\section{Conclusions}

Cellular profile in herpetic urethritis is characterized by elevation of lymphocytes, expressing marker of early activation $\left(\mathrm{CD} 25^{+}\right)$at the normal value of the cells, carrying HLA-DR antigen, and elevation of cells, able to apoptosis, evidencing of the switch disturbances in the activation processes from the early to the late one and reflect T-cell immunity functional defect. In the venous blood serum, there was noted reliable increasing of the level of anti-inflammatory mediator $\mathrm{TNF} \alpha$, though in the ejaculate this index is statistically reliable and no different from the control. Reducing of the IFN $\gamma /$ IL-10 ratio was evaluated both in the venous blood serum, and in the male semen comparing with the control group, evidencing dysregulation of the immune response on the local and systemic levels in this patient category.

In the mixed bacterial-viral urethritis, significant increase of $\mathrm{CD} 3+\mathrm{CD} 25+$ expression and augmentation of the indices of the late negative activation markers have been found, with the declining of the phagocytosis indices, reflecting presence of the signs of the chronic cellular activation, as well as evidencing T-lymphocyte high readiness to induction-activation apoptosis in this patient category. In the venous blood serum, there was noted significant increasing of the level of anti-inflammatory mediator TNF $\alpha$; in the ejaculate, this cytokine level was also significantly increased comparing the male group with herpetic urethritis and the group of control, it was this mixed 
bacterial-viral urethritis group under the investigation that had this indicator of high apoptotic activity, contributing the maintenance of chronic inflammation and fertility disturbances. Both in venous blood serum and in the ejaculate, IFN $\gamma$ level was close to the reference values. IFN $\gamma / \mathrm{IL}-10$ ratio decreasing was evaluated as in the venous blood serum, and in the semen, comparing the control group.

\section{Summary}

Under the conditions of the persistent viral-bacterial urogenital infection, immune homeostasis is of great importance. It was estimated that qualitative alteration throughout the infectious process was observed, as interaction of the causative agents could significantly exchange their pathogenic characteristics, in consequence of this, the immunological and clinical patterns were able to obtain definite peculiarities and vary significantly from those, inherent to certain monoinfections.

\section{References}

[1] Egorov, Y. V., Nesterov, A. S., Ilyina, N. A., and
Nesterova, A. V. 2012. "Features of the Immune System in Women, Patients with Urogenital Chlamydiosis." Bulletin of the Chuvash State Pedagogical University Named after I.Ya. Yakovlev 4 (76): 69-73. (in Russian)

[2] Plakhova, K. I., Frigo, N. V., Rakhmatulina, M. R., Rotanov, S. V., and Hajrullin, R. F. 2012. "Immune Predictors of Complications of the Urogenital Chlamydial Infection Leading to Infertility." Bulletin of Dermatology and Venereology 4: 41-7. (in Russian)

[3] Karaulov, A. V., and Yutskovskiy, A. D. 2013. Clinical Immunology in Dermatovenerology and Cosmetology. Vladivostok: Far-Eastern Medicine, 204.

[4] Markelova, E. V., Sklyar, L. F., Prosekova, E. V., Chepurnova, N. S., Nagornaja, A. V., Li, Ju. A., and Gorelova, I. S. 2016. Persistent Viral Infections: Etiology and Immunopathogenesis: Monograph, edited by Markelova, E. V. Far-Eastern Medicine, 160.

[5] Petrova, L. I., and Yutskovskiy, A. D. 2014. "Medico-Social Study of Young Working Age Persons Suffering from Sexually Transmitted Infections in the Republic of Sakha (Yakutia)." Pacific Medical Journal 2: 74-6.

[6] Yarilin, A. A. 2010. Immunology. Moscow: GEOTAR-Media, 752.

[7] Allam, J. P., Fronhoffs, F., Fathy, A. Novak, N., Oltermann, I., Bieber, T., Schuppe, H.-C., and Haidl, G. 2008. "High Percentage of Apoptotic Spermatozoa in Ejaculates from Men with Chronic Genital Tract Inflammation." Andrologia 40 (5): 329-34. 